\title{
"Effect of Acupressure on Sleep Quality Among Patients with Acute Coronary Syndrome at Assiut University Heart Hospital"
}

\author{
Asmaa Atiaa Tolba ${ }^{1}$, Warda Youssef Mohammed ${ }^{2}$, Mona Aly Mohammed ${ }^{3}$, Mogedda Mohamed Mehany ${ }^{4}$, \\ \& Ahmed Abdel-Galeel ${ }^{5}$. \\ ${ }^{1}$ Assistant lecturer of Critical Care \& Emergency Nursing, Faculty of Nursing, Assiut University, Egypt. \\ ${ }^{2}$ Professor of Critical Care \& Emergency Nursing, Dean of Faculty of Nursing, Cairo University, Egypt. \\ 3 Assist. Professor of Critical Care \& Emergency Nursing, Faculty of Nursing, Assiut University, Egypt. \\ ${ }^{4}$ Assist. Professor of Critical Care \& Emergency Nursing, Faculty of Nursing, Assiut University, Egypt. \\ ${ }^{5}$ Lecturer of Cardiology, Faculty of Medicine, Assiut University, Egypt.
}

\begin{abstract}
Background: Acupressure decreases muscular tension, enhancing blood circulation, makes deep relaxation and improving sleep quality. Aim: to investigate effect of acupressure on sleep quality among patients with acute coronary syndrome (ACS). Design: a quasi-experimental design. Setting: Coronary Care Unit at Assiut University Heart Hospital. Subjects: Convenience sample of 60 male and female adult patients were assigned randomly to two equal groups (30 each). Tools: two tools were utilized to collect study data, Tool I Acute Coronary Syndrome patient assessment Tool II: Modified ST Mary’s Hospital Sleep Questionnaire (SMHSQ). Methods: Researcher assessed homodynamic status of both groups every four hours as base line data and for 3 consecutive days. Then, acupressure was applied for study group between 7:10 PM. On morning, sleep quality was assessed for both groups by using modified (SMHSQ) between 7:8 AM. Results: Finding of this study supported stated research hypotheses with statistical significant difference between study and control groups regarding sleep quality on $1^{\text {st }}, 2^{\text {nd }}$ and $3^{\text {rd }}$ nights of intervention $\left(\mathrm{P}=0.000^{* *}, \mathrm{P}=0.000^{* *}\right.$ and $\mathrm{P}=0.000^{* *}$ ) respectively. Conclusion Acupressure can significantly improve sleep quality of ACS patients. Therefore, Utilization of acupressure as a basic part of care provided to all ACS patients is highly recommended.
\end{abstract}

Key words: Acupressure \& Sleep Quality Acute Coronary Syndrome Patients.

\section{Introduction}

Sleep is a basic requirement for patients with acute coronary syndrome (ACS) to recover and maintain their proper physical and psychological health. Sleep consisted of two phases which include Rapid Eye Movement (REM) and non-REM sleep. Non- rapid eye movement sleep (NREM) can separated into phases 1, 2, 3 and 4. The NREM and REM sleep cycles exchange for the duration of the night. Sleep beginning normally happens in phase 1 sleep, advancing through phases 2, 3 and 4, and then return to phase 2 , in this time the individual generally enters REM. The primary cycle regularly continues for 70 to 100 minutes, while later cycles taking 90 to 120 minutes. Normal adult sleep is finished in 4 to 5 cycles. (Waterhouse et al., 2012)

The etiologies of sleep disturbance in coronary care units (CCU) including underlying diseases, medications side effect and psychological problems. In additional to, other controllable causes as noise, light, and patient care interactions. Sleep disturbance, for more than one night, increase the discharge of inflammatory cytokines that raise endothelial disruptions related to atherosclerosis, hypertension, and acute coronary artery syndrome (Sauvet et al., 2010 \& Daneshmandi et al., 2012 \& Mullington et al., 2012).
Sleep disturbance in patients with ACS usually begin at the end of the first day of hospitalization. Sleep disturbance is commonly in patients with ACS during the initial 3 days of their hospitalization. Sleep disturbance in patients with ACS can negatively effect on many physiological functions necessary for recovery, including tissue repair, cellular immune function, resistance to infection, cardiorespiratory, neurological, endocrine, metabolic functions and energy balance (Schiza et al., 2010\&Bihari et al., 2012 \& Zolfaghari et al., 2013).

Critical care nurses apply different alternative or complementary health methods for assisting patients with ACS to overcome their sleep disturbance such as; acupressure, mental imagery, relaxation techniques, music therapy and massage. Acupressure is a traditional art in Chinese medicine, in this technique of treatment fingers are utilized for pressing the key points on the skin surface for activating and inducing body's natural self-healing abilities (Oshvandi et al., 2014 \& Reed, 2014).

Acupressure help patient to sleep through massaging and activating some points in the head, hands and legs. The uses of acupressure technique assisting in reducing pain, balancing body energy, and meantaining better health. Acupressure's healing 
touch decreases muscular tension, enhances blood circulation, and makes deep relaxation and improving sleep (Carotenuto et al., 2013\& Waits et al., 2016)

\section{Significance of the study}

In Assiut University Heart Hospital, 1180 patients approximately admitted to CCU with ACS in 2014. sleep disturbance in patients with ACS has been associated with negative consequences on patient health and recovery from illness. However, sleep in patient with ACS can be deprioritized because of the care mostly directed for oxygenation, improving of tissue perfusion and maintaining homodynamic status within normal. The incidence of sleep disturbance in the coronary care unit is difficult to quantify due to poor documentations when compared to other health problems. Although, sleep disturbance is considered critical problem face patients with ACS, this area of care is neglected in the field of nursing researches at Assiut University.

\section{Aim of the study}

- To investigate the effect of acupressure on sleep quality among patients with acute coronary syndrome at Assiut University Heart Hospital.

\section{Hypothesis}

- To fulfill the aim of this study the following research hypothesis was formulated:- Acute coronary syndrome patients will demonstrate statistical significant improvement in sleep quality with the use of acupressure when compared to control group subject.

\section{Patients \& methods \\ Research design}

Quasi-experimental research design was used to conduct this study. This design used to explain relationships, clarify certain events happened or both (Polit \& Beck, 2012).

\section{Setting}

This study was carried out in Coronary Care Unit (CCU) that containing (16 beds in 3 separated rooms, 6 head nurses, 40 nurses, 4 nurse assistants, flow patient rate 6 patients daily approximately, nurse patient ratio 1:3) at Assiut University Heart Hospital.

\section{Sampling}

A convenience sampling of 60 adult male and female patients with acute coronary syndrome were constituted the study sample. The subjects were randomly assigned into two equal groups (study group and control group, 30 patients each) considering the following matching criteria age group, sex, level of education, diagnosis and comorbidity. Both groups received the routine hospital care.

\section{Inclusion criteria}

This study included patients had the following criteria

- Age over 18 to 60 years.

- Fully conscious patient

- Have had one previous night in the unit during this hospital stay

\section{Exclusion criteria}

This study excluded those who had the following criteria:-

- Mentally ill patients

- Leg amputation at the site of the acupressure points Tools

Two tools were used by the researcher in this study after reviewing of the related literatures (Ellis et al., 1981 Leigh et al., 1988 \& Moeini et al., 2010 \& Shahid et al., 2012\& Oshvandi et al., 2014 \& Bagheri-Nesami et al., 2015 \& Delaney et al., 2015) to investigate the effect of acupressure on sleep quality among patients with acute coronary syndrome.

Tool (1): Acute coronary syndrome patient assessment

- This tool was developed by the researcher after reviewing of the related literatures (Oshvandi et al., 2014 \& Bagheri-Nesami et al., 2015 \& Delaney et al., 2015). This tool consisted of thirteen items. It was used to assess the studied patients regarding demographic, clinical data, habits and homodynamic state to form base line data to be compared with. This tool comprised two main parts:

Part I: Demographic and clinical data

Demographic data included patient's age, sex, level of education. clinical data as patient's diagnosis, , past medical history and history of previous hospitalization in ICU, the patient's experience in using sleep aids and their experience with using complementary medicine. In additional to, habits such as drinking tea and coffee (Oshvandi et al., 2014 \& Bagheri-Nesami et al., 2015).

Part II: Homodynamic parameters sheet

This part included pulse, blood pressure, respiration and temperature (Delaney et al., 2015)

Tool (2): Modified ST Mary's Hospital Sleep Questionnaire (SMHSQ)

This tool was developed by Ellis et al., (1981) \& Leigh et al., (1988) then modified by the researcher. ST Mary's Hospital Sleep Questionnaire is a sleep systematic questionnaire is designed for evaluating sleep status of the hospitalized patients. It included fourteen items for assessing the duration and subjective quality of an individual's previous night's sleep and it can be repeated again. As the scale solicits both likert type and a fill-in-the-blank response. The questions were about the amount of a 
day and night sleep, depth of sleep, waking numbers during sleep, sleep quality, the amount of waking consciousness, the amount of satisfaction with sleep, troubling by waking early and difficulty in getting off to sleep. This questionnaire had been evaluated in many studies. For example Moeini et al., (2010) used this questionnaire and achieved its reliability 0.91 and Oshvandi et al., (2014) used this questionnaire and achieved its reliability 0.87 and in this study, reliability was 0.781 by using Cronbach's alpha. (Moeini et al., 2010, Shahid et al., 2012 \& Oshvandi et al., 2014)

The researcher modified first four questions from open ended questions to closed questions. An answer of the first and second questions arranged in four chooses while an answer of third and fourth questions arranged in three chooses.

The scale's scoring process has not been standardized grading for this questionnaire. The SMHSQ questionnaire was scored in the present study, based on the opinion of experts and specialists. In this study the SMHSQ questionnaire divided to two parts; part one reflected duration of sleep and presented in questions $(1,2,3,4,7,8$ and14) while part two reflected sleep quality and presented in questions $(5,6,9,10,11,12$, and13). Scores are between 6 and 38 which reflected part two of the SMHSQ questionnaire. A score of 6-16, a severe sleep disorder; a score of 17-28, a moderate sleep disorder; and a score of 29-38 a slight sleep disorder (Ellis et al., 1981 \& Leigh et al., 1988 \& Shahid et al., 2012).

\section{Method}

The study was conducted throughout three main phases, which were preparatory phase, implementation phase and evaluation phase

Preparatory phase

- Permission to conduct this study obtained from the responsible hospital authorities in cardiology department after explaining the aim and nature of the study.

- Protection of human rights (ethical considerations):

- Research proposal approved from Ethical Committee in the Faculty of Nursing.

- There was no risk for study subject during application of the research

- The study was followed common ethical principles in clinical research.

- Written consent was obtained from patients or guidance that were willing to participate in the study, after explaining the nature and purpose of the study.

- Confidentiality and anonymity assured.

- Study subject had the right to refuse to participate and/or withdraw from the study without any rational any time.
- Study subject privacy was considered during collection of data.

- Tool one in this study was developed by the researcher based on reviewing the relevant literature.

- Tool two in this study was translated into Arabic by the researcher after modification for testing validity and reliability.

- Content validity: Tools was tested for content validity by a jury of (5) specialists in the field of critical care nursing and cardiology from Assiut University, and necessary modifications was done.

- The Reliability was done on tool two by Cronbach`s Alpha $(\mathrm{r}=0.781)$ to assess the consistency and stability of the tools.

- A pilot study was conducted on 6 patients in order to assess the feasibility and applicability of the tools and the necessary modifications was done.

- Training programme on acupressure technique:

- Training was conducted to the researcher by more than specialists professional in Physiotherapy Unit at Assiut University Hospital in four sessions, 2 sessions per week for 2 consecutive weeks, and each session constituted of three hours from 9 am to $12 \mathrm{pm}$ and then they approved researcher ability to implement the acupressure technique without assistance.

- In first session, trainer explained acupressure definition, advantages, key points for improving sleep quality, and acupressure technique.

- In second session, trainer demonstrated acupressure technique and researcher re-demonstrated acupressure technique.

- In third session and fourth session, the researcher applied acupressure technique and the trainer gave its comments. Finally, trainer approved to researcher to apply acupressure technique.

Data collection

- Intervention for the studied patients was initiated on the second night of hospitalization. There was no intervention on the first night of hospitalization because of the patients' acute conditions. Data was completed for 4 days (the 1st day of hospitalization concerning first night of sleep in the hospital and 3 days of intervention).

- Data were collected over nine months approximately starting from February 2016 to October 2016.

Implementation phase for the study and control groups

- The aims of the study were explained to the patients.

- For study and control groups

- During this phase the researcher assessed patients from the first day of admission and record patient 
demographic, clinical data and habits before any data collection by taking this information from their sheets using tool 1 (Part 1).

- The researcher assessed homodynamic state of the study and control groups (pulse, respiration, blood pressure and temperature ) every four hours daily by using tool 1(part 2) for four days to assess effects of sleep deprivation.

- For acupressure group:

- Patients in the acupressure group received acupressure in the Wind Pool point behind the head, the glabella point in the forehead, the ear Shenmen, the wrist spirit gate, and the Gushing Spring in the soles of the feet bilaterally.

- They received acupressure with a pressure of approximately $3: 4 \mathrm{~kg}$ in every point, and they received a 2-minutes massage for every point with the thumb. This amounted in total to 18 minutes for nine points for three consecutive nights between 7 PM and 10 PM. (Bagheri-Nesami et al., 2015)

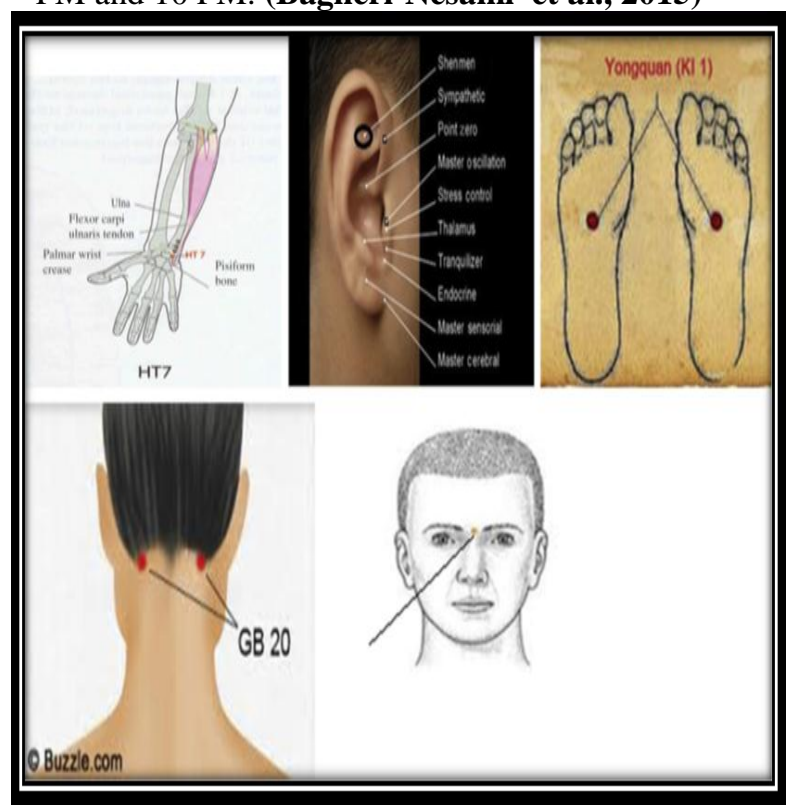

Points selected for massage in the actual acupressure points adopted from Bagheri-Nesami et al., (2015)

\section{Evaluation phase}

This phase was done to evaluate sleep quality for the study and control groups by using modified ST Mary's Hospital Sleep questionnaires which was completed every day in the morning between 7 AM and $8 \mathrm{AM}$ for 4 days (the $1^{\text {st }}$ day of hospitalization concerning first night of sleep in the hospital and 3 days of intervention).

\section{Statistical analysis}

- Data were computerized and analyzed by computer programme Data was collected and analyzed by computer programmed SPSS (ver.16) .Data were presented using descriptive statistics in the form of frequencies and percentages for qualitative variables, and means and standard deviations for qualitative variables. Quantitative continuous data were compared using Independent samples t- test for comparisons among two groups. Qualitative variables were compared using chi-square test to determine significance.

- The critical value of the tests "P" was considered statistically significant when $\mathrm{P}$ less than 0.05 .

\section{Limitation of the study}

- It was difficult for the researcher to assess sleep stages of ACS patients which was positively beneficial to this study but it couldn't be reached because of the unavailability of polysomnography in CCU.

- Lack of Egyptian statistical record about sleep quality of acute coronary syndrome patients. 
Results

- The current study was aimed to investigate the effect of acupressure on sleep quality among patients with acute coronary syndrome at Assiut University Heart Hospital.

To accomplishing the aim of this study the following research hypothesis was stated:

- Acute coronary syndrome patients will demonstrate improvement in sleep quality with the use of acupressure when compared to control group subject.

Results of the current study are presented in two sections:-

- Section I: Delineated demographic and clinical data: Tables (1-3) and figure (1) are related to this section.

- Section II: Affiliated to the testing of research hypotheses (I). Tables (4-5) are related to this section.

Section I: Demographic and medical data of patients

Table (1): Comparison between the study and control groups in relation to demographic data.

\begin{tabular}{|c|c|c|c|c|c|}
\hline \multirow[t]{2}{*}{ Items } & \multicolumn{2}{|c|}{$\begin{array}{c}\text { Study group } \\
(n=30)\end{array}$} & \multicolumn{2}{|c|}{$\begin{array}{c}\text { Control group } \\
(n=30)\end{array}$} & \multirow[t]{2}{*}{ P. value } \\
\hline & No & $\%$ & No & $\%$ & \\
\hline \multicolumn{6}{|l|}{ Age: (years) } \\
\hline$<40$ years & 2 & 6.6 & 2 & 6.6 & \multirow{3}{*}{0.637} \\
\hline $40-<50$ years & 5 & 16.6 & 8 & 26.6 & \\
\hline $50-60$ years & 23 & 76.6 & 20 & 66.6 & \\
\hline Mean \pm SD(year) & \multicolumn{2}{|c|}{$52.6 \pm 6.7$} & \multicolumn{2}{|c|}{$52.2 \pm 6.2$} & \\
\hline \multicolumn{6}{|l|}{ Level of education } \\
\hline Read and write & 13 & 43.3 & 9 & 30.0 & \multirow{4}{*}{0.050} \\
\hline Primary education & 7 & 23.3 & 9 & 30.0 & \\
\hline Secondary education & 6 & 20.0 & 1 & 3.3 & \\
\hline Bachelor & 4 & 13.3 & 11 & 36.7 & \\
\hline
\end{tabular}

- Independent samples t-test - Chi-square test $*$ significant difference at $p$. value $<0.05$

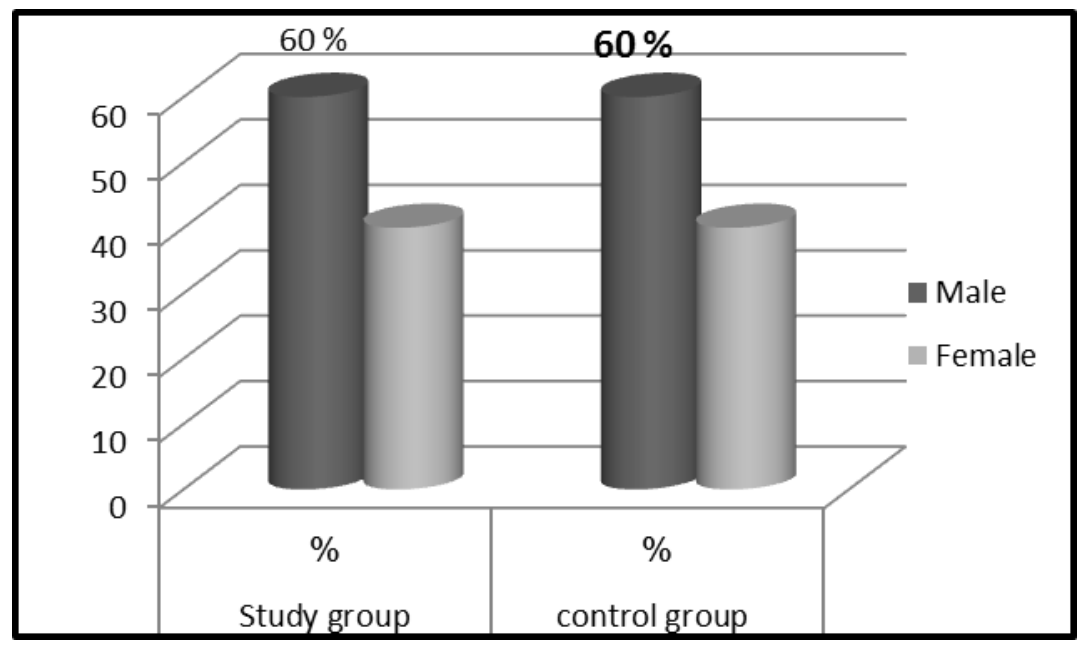

Figure (1): Percentage distribution of the study and control groups in relation to gender. 
Table (2): Comparison between the study and control groups in relation to clinical data and previous habits.

\begin{tabular}{|c|c|c|c|c|c|}
\hline \multirow{2}{*}{ Items } & \multicolumn{2}{|c|}{ Study $\operatorname{group}(n=30)$} & \multicolumn{2}{|c|}{ Control group $(n=30)$} & \multirow[t]{2}{*}{ P. value } \\
\hline & No & $\%$ & No & $\%$ & \\
\hline \multicolumn{6}{|l|}{ Diagnosis } \\
\hline Unstable angina & 9 & 30.0 & 6 & 20.0 & \multirow{3}{*}{0.637} \\
\hline - NSTEMI & 2 & 6.7 & 3 & 10.0 & \\
\hline - STEMI & 19 & 63.3 & 21 & 70.0 & \\
\hline \multicolumn{6}{|l|}{ Past medical history } \\
\hline No history & 13 & 43.3 & 14 & 46.7 & \multirow{4}{*}{0.762} \\
\hline Hypertension & 9 & 30.0 & 8 & 26.7 & \\
\hline Diabetes mellitus & 0 & 0.0 & 1 & 3.3 & \\
\hline Hypertension + Diabetes mellitus & 8 & 26.7 & 7 & 23.3 & \\
\hline \multicolumn{6}{|c|}{ History of previous hospitalization in ICU } \\
\hline No & 25 & 83.3 & 22 & 73.3 & \multirow{2}{*}{0.532} \\
\hline Yes & 5 & 16.7 & 8 & 26.7 & \\
\hline \multicolumn{6}{|c|}{ Experience in using sleep aids and complementary medicine } \\
\hline No & 30 & 100 & 30 & 100 & \multirow{2}{*}{-} \\
\hline Yes & 0 & 0 & 0 & 0 & \\
\hline \multicolumn{6}{|l|}{ Habits: drinking tea and coffee } \\
\hline No & 8 & 26.7 & 9 & 30.0 & \multirow{2}{*}{1.000} \\
\hline Yes & 22 & 73.3 & 21 & 70 & \\
\hline
\end{tabular}

Chi-square test

* Significant difference at $p$. value $<0.05$

NSTEMI: non ST-segment elevation myocardial infarction STEMI: ST-segment elevation myocardial infarction

Table (3): Comparison between the study and control groups in relation to hemodynamic parameters mean scores.

\begin{tabular}{|c|c|c|c|}
\hline Items & $\begin{array}{l}\text { Study group } \\
\quad(n=30)\end{array}$ & $\begin{array}{l}\text { Control group } \\
\quad(n=30)\end{array}$ & P. value \\
\hline \multicolumn{4}{|l|}{$\overline{\text { Pulse }}$} \\
\hline $1^{\text {st }}$ day of hospitalization & $84.2 \pm 12.5$ & $88.6 \pm 15.4$ & 0.229 \\
\hline $1^{\text {st }}$ day of intervention & $78.5 \pm 10.8$ & $82.4 \pm 12.8$ & 0.207 \\
\hline $2^{\text {nd }}$ day of intervention & $78.9 \pm 10.2$ & $81.5 \pm 11.7$ & 0.362 \\
\hline $3^{\text {rd }}$ day of intervention & $79.7 \pm 7.9$ & $78.8 \pm 9.6$ & 0.693 \\
\hline \multicolumn{4}{|l|}{ SBP } \\
\hline $1^{\text {st }}$ day of hospitalization & $131 \pm 15.4$ & $126.3 \pm 19.2$ & 0.299 \\
\hline $1^{\text {st }}$ day of intervention & $124.3 \pm 19.2$ & $120 \pm 18.4$ & 0.379 \\
\hline $2^{\text {nd }}$ day of intervention & $121.7 \pm 15.3$ & $118 \pm 14.2$ & 0.335 \\
\hline $3^{\text {rd }}$ day of intervention & $121 \pm 12.4$ & $120.3 \pm 11.9$ & 0.824 \\
\hline \multicolumn{4}{|l|}{ DBP } \\
\hline $1^{\text {st }}$ day of hospitalization & $81.7 \pm 10.5$ & $80.3 \pm 11.3$ & 0.621 \\
\hline $1^{\text {st }}$ day of intervention & $80.3 \pm 12.7$ & $79.7 \pm 15$ & 0.867 \\
\hline $2^{\text {nd }}$ day of intervention & $79 \pm 9.6$ & $78 \pm 11.9$ & 0.721 \\
\hline $3^{\text {rd }}$ day of intervention & $77.7 \pm 9$ & $79.3 \pm 8.3$ & 0.477 \\
\hline \multicolumn{4}{|l|}{ MBP } \\
\hline $1^{\text {st }}$ day of hospitalization & $98.1 \pm 11.3$ & $95.7 \pm 13.2$ & 0.452 \\
\hline $1^{\text {st }}$ day of intervention & $95 \pm 14.5$ & $93.1 \pm 15.8$ & 0.629 \\
\hline $2^{\text {nd }}$ day of intervention & $93.2 \pm 11.3$ & $91.3 \pm 12.1$ & 0.532 \\
\hline $3^{\text {rd }}$ day of intervention & $92.1 \pm 10$ & $93 \pm 9.2$ & 0.721 \\
\hline \multicolumn{4}{|l|}{ RR } \\
\hline $1^{\text {st }}$ day of hospitalization & $22.7 \pm 2.2$ & $22.3 \pm 2.1$ & 0.474 \\
\hline $1^{\text {st }}$ day of intervention & $19.3 \pm 1.8$ & $21.1 \pm 1.7$ & $0.000 * *$ \\
\hline
\end{tabular}




\begin{tabular}{|l|c|c|c|}
\hline \multicolumn{1}{|c|}{ Items } & \multicolumn{1}{|c|}{$\begin{array}{c}\text { Study group } \\
(\mathbf{n = 3 0 )}\end{array}$} & $\begin{array}{c}\text { Control group } \\
(\mathbf{n = 3 0 )}\end{array}$ & P. value \\
\hline $2^{\text {nd }}$ day of intervention & $17.9 \pm 1.7$ & $19.9 \pm 2.7$ & $0.001^{* *}$ \\
\hline $3^{\text {rd }}$ day of intervention & $16.6 \pm 1.5$ & $19.2 \pm 2.1$ & $<0.001^{* *}$ \\
\hline Temperature & \multicolumn{3}{|l|}{} \\
\hline $1^{\text {st }}$ day of hospitalization & $37 \pm 0.2$ & $36.9 \pm 0.5$ & 0.313 \\
\hline $1^{\text {st }}$ day of intervention & $37.1 \pm 0.4$ & $37 \pm 0.4$ & 0.336 \\
\hline $2^{\text {nd }}$ day of intervention & $37 \pm 0.2$ & $37 \pm 0.4$ & 1.000 \\
\hline $3^{\text {rd }}$ day of intervention & $36.9 \pm 0.2$ & $36.9 \pm 0.3$ & 1.000 \\
\hline
\end{tabular}

- Independent samples $t$-test $*$ significant difference at $p$. value $<0.05$

SBP: Systolic Blood Pressure DBP: Diastolic Blood Pressure MBP: Mean Blood Pressure

RR: Respiratory rate

Section II: The testing of research hypotheses (I) Acute coronary syndrome patients will demonstrate statistical significant improvement in sleep quality with the use of acupressure when compared to control group subject.

Table (4): Comparison between the study and control groups in relation to duration of night sleep mean scores (average hours and minutes).

\begin{tabular}{|l|c|c|c|}
\hline \multicolumn{1}{|c|}{ Items } & $\begin{array}{c}\text { Study group } \\
(\mathbf{n = 3 0})\end{array}$ & $\begin{array}{c}\text { Control group } \\
(\mathbf{n = 3 0})\end{array}$ & P. value \\
\hline $1^{\text {st }}$ night of hospitalization & $1.18 \pm 1.15$ & $1.1 \pm 0.92$ & 0.767 \\
\hline $1^{\text {st }}$ night of intervention & $4 \pm 1.26$ & $2.17 \pm 1.85$ & $\mathbf{0 . 0 0 1} * *$ \\
\hline $2^{\text {nd }}$ night of intervention & $4.7 \pm 0.88$ & $3.13 \pm 1.32$ & $<\mathbf{0 . 0 0 1} * *$ \\
\hline $3^{\text {rd }}$ night of intervention & $4.9 \pm 0.84$ & $3.32 \pm 1.37$ & $<\mathbf{0 . 0 0 1} * *$ \\
\hline
\end{tabular}

- Independent samples t-test

* Significant difference at p. value $<0.05$

Table (5): Comparison between the study and control groups in relation to total sleep quality mean scores.

\begin{tabular}{|l|c|c|c|}
\hline \multicolumn{1}{|c|}{ Items } & $\begin{array}{c}\text { Study group } \\
(\mathbf{n = 3 0 )}\end{array}$ & $\begin{array}{c}\text { Control group } \\
(\mathbf{n = 3 0})\end{array}$ & P. value \\
\hline $1^{\text {st }}$ night of hospitalization & $17.27 \pm 1.53$ & $17.03 \pm 0.76$ & 0.458 \\
\hline $1^{\text {st }}$ night of intervention & $22.77 \pm 3.52$ & $18.37 \pm 2.33$ & $\mathbf{0 . 0 0 0} * *$ \\
\hline $2^{\text {nd }}$ night of intervention & $23.53 \pm 2.67$ & $20.47 \pm 2.86$ & $\mathbf{0 . 0 0 0} * *$ \\
\hline $3^{\text {rd }}$ night of intervention & $23.6 \pm 2.65$ & $20.46 \pm 2.67$ & $\mathbf{0 . 0 0 0} * *$ \\
\hline
\end{tabular}

- A score of 6-16, a severe sleep disorder

- A score of 17-28, a moderate sleep disorder

- A score of 29-38 a slight sleep disorder

Table (1): Represents that two third of both groups their age ranged between 51:60 years old with no statistical significant difference between study and control groups in relation to age $(76.6 \%$ and $66.6 \%)$ respectively .For level of education the highest percentage of both groups can read and write $(43.3 \%$ and $30 \%$ ) respectively.

Figure (1): Shows that more than half of both groups were males with no statistical significant difference between them (60\% and 60\%) respectively.

Table (2): Shows that more than half of both groups were diagnosed as ST-segment elevation myocardial infarction $(63.3 \%$ and $70.0 \%)$ respectively.
Furthermore, near to quarter of the study and control groups had past history of hypertension and diabetes (26.7\% and $23.3 \%)$ respectively. No statistical significant difference between the study and control groups in relation to all items mentioned in this table ( $\mathrm{P}$ value $>0.05$ ).

Table (3): Reveals that the mean scores of pulse, systolic blood pressure, diastolic blood pressure, mean blood pressure and temperature was within normal for both groups all over the four assessments with no significant difference except in respiration $(\mathrm{P}=<0.001)$. 
Table (4): Illustrates that there was gradual increase in duration of night sleep mean scores for both groups with a statistical significant difference between them in $1^{\text {st }}, 2^{\text {nd }}$ and $3^{\text {rd }}$ nights of intervention $(\mathrm{P}=0.001 * * \& \mathrm{P}=<0.001 * * \& \mathrm{P}=<$ $0.001 * *)$ respectively.

Table (5): Illustrates that the study and control groups had moderate sleep disorder because the average score 17-28 while study group had a statistical significant improvement in total sleep quality mean scores when compared with control group in $1^{\text {st }}, 2^{\text {nd }}$ and $3^{\text {rd }}$ nights of intervention $(\mathrm{P}=0.000 * *, \mathrm{P}=0.000 * * \& \mathrm{P}=0.000 * *)$ respectively. Thus hypothesis (1) can be supported

\section{Discussion}

Patients in CCU usually complain from sleep disturbance in forms of difficulty falling asleep, fragmentation of sleep and decline in REM sleep. Critical care nurse in CCU must initially recognize sleep disturbance, etiologies of sleep disturbance, consequences of sleep disturbance and nursing management of sleep disturbance to improve ACS patient's sleep quality. One of the effective techniques that have been progressively utilized in recent years is complementary or alternative techniques as acupressure. The effective acupressure can improve sleep quality by relieving stress, anxiety and pain ((Jafarian et al., 2011). This study aimed to evaluate the effect of acupressure on sleep quality among patients with acute coronary syndrome at Assiut University Heart Hospital.

The current study presented that two third of both groups were in age group 50 to 60 years old and most of them were males. This might be related to changes in the heart and blood vessels with aging. Also, this can be attributed to the fact that males are the higher exposure to life stress, and female's hormones protect females from ACS. This was supported with Moeini et al., (2010) who studied effect of aromatherapy on the quality of sleep in ischemic heart disease patients hospitalized in intensive care units of heart hospitals of the Isfahan University of Medical Sciences documented that more than half of experiment and control groups were males $(65.6 \%, 59.4 \%)$ respectively. Also, the mean age of experiment and control groups was $(55.7 \pm 7.7$ and $52.8 \pm 8.5)$ respectively.

The present study, demonstrated that more than half of study and control groups were diagnosed with STEMI. This might be related to cardiovascular diseases, such as angina pectoris and myocardial infarction, can cause disturbance of sleep and considering that myocardial oxygen need is high due to sleep disturbance. This was in according with Mashayekhi et al., (2013) who studied the effect of eye mask on sleep quality in patients of CCU found that less than half study sample (34) were admitted to CCU due to STEMI.

The findings of the current study revealed that half of both groups had past history of hypertension only or hypertension and diabetes. This might be related to the fact that ACS is the most common complication of hypertension and diabetes mellitus. In this respect Neyse et al., (2011) who studied the effect of earplugs on sleep quality in patients with ACS reported that $35 \%$ of the samples had previous history of hypertension, $25 \%$ had previous history of diabetes and $21.6 \%$ had a previous history of both.

The current study documented that, more than two third of the study and control groups weren't had previous history of hospitalization. This might attributed that it was the first sudden onset of heart attack and that might be one of factors effecting on sleep quality of both groups especially in first night of hospitalization. This was in contrast with BagheriNesami et al., (2015) who studied effect of acupressure with valerian oil $2.5 \%$ on the quality and quantity of sleep in patients with ACS in a cardiac intensive care unit found that $68.3 \%$ of patients had a previous history hospitalization.

The finding of the current study revealed that all of the study and control groups did not use sleep aids. This result was in contrast with a study conducted by Oshvandi et al., (2014) who studied the effect of foot massage on quality of sleep in ischemic heart disease patients hospitalized in $\mathrm{CCU}$ reported that $13.3 \%$ of studied sample had history of using sleep medications.

The current study presented that more than two third of the study and control groups consuming coffee and tea. These substances can effect on sleep quality. Caffeine can damage REM sleep. Even so, these substances obligatory stopped during the hospital stay which may cause sleep deprivation. This was in line with Viana \& Filomena, (2014) who studied factors that affect inpatients' quality of sleep reported that nicotine causes a delay in falling asleep but, on the other face, sudden abstinence may cause sleep disturbance for more than one night.

Although there was effect of acupressure on hemodynamic status of study groups but it wasn't reach to level of statistical difference. This might be attributed that half of the study and control groups received Beta blocker agents and AngiotensinConverting Enzyme (ACE) inhibitors. Beta blocker agents decrease myocardial contractility, pulse and blood pressure. The ACE inhibitors block the reninangiotensin- aldosterone system, reduce afterload, and reduce blood pressure. Moreover, the majority of the study and control groups received vasodilators agents as meanly nitrates. Hypotension, considerate 
the most common side effect of nitrates (Lewis et al., 2014).

The present study also revealed a significant reduction of respiratory rate from the first to the last night of intervention among both groups. This improvement might be related to improvement of sleep quality and increasing of sleep duration. This result was in accordance with a study conducted by Lytle et al., (2016) who studied effect of lavender aromatherapy on vital signs and perceived quality of sleep in the intermediate care unit: a pilot study documented that positive correlation between sleep and blood pressure, pulse, and respiratory rate.

Sleep disturbance can be treated by medication, complementary or alternative therapy, and psychological or physical therapy. Acupressure is an effective complementary or alternative therapy enhancing comfort and sleep. The potent acupressure points for sleep in the head, hands, and legs can improve the quality of sleep by getting rid of stress, acupressure therapy reinforces protection from diseases and improves wellness. Patients can use this method by themselves or with the help of other health care team (Wang et al., 2013\& Yeung et al., 2012).

Results of the current study revealed that the total sleep quality mean scores for acupressure group was significantly improved from the first to third nights of intervention as well as there was gradual significantly increase in duration of night sleep mean scores. This improvement might be related to effective applying of acupressure technique which assisted study group patients to be relaxed and sleep deeply .This finding is supported by the results of Chen et al., (2012) who studied the effectiveness of valerian acupressure on the sleep of ICU patients: a randomized clinical trial reported that increasing sleep hours of patients, improving sleep quality and reducing wake frequency after receiving valerian acupressure.

This finding was consistent with, Shariati et al., (2012) who studied the effect of acupressure on sleep quality in hemodialysis patients documented that the positive effect of acupressure in improving sleep quality of renal disease patients. Furthermore, Abedian et al., (2015) who studied the effect of acupressure on sleep quality in menopausal women: A randomized control trial documented that acupressure can be used to improve sleep quality in menopausal women.

Finally, the major finding of this study was that applying acupressure significantly improve total sleep quality mean scores and duration of night sleep mean scores.

\section{Conclusion \& Recommendations}

Based on the results of this study, it can be concluded that acupressure are convenient and safe method that can significantly improve sleep quality of ACS patients with few to zero adverse effects.

Based on the study findings, the following

\section{Recommendations are suggested}

- Emphasize have be directed toward; importance of assessing sleep quality for early detection of any sleep disturbance and utilization of acupressure technique as a basic part of care provided to all ACS patients in coronary care units.

- Equip the coronary care unit with simple illustrated protocol regarding acupressure technique and it's an important role in relieving sleep disturbance.

- Improve documentation of sleep disturbance in a record, to measure the size of this problem accurately.

- Studying different methods of alternative or complementary medicine to improve the patients' quality of sleep, which results in improving patients' health.

\section{References}

1. Abedian Z., Eskandari L., Abdi H., \& Ebrahimzadeh S., (2015): The Effect of Acupressure on Sleep Quality in Menopausal Women: A Randomized Control Trial. Iranian Journal of Medical Sciences; 40(4): 328-334.

2. Bagheri -Nesami M., Ali M., Rezaie S., Pouresmail3 Z., \& Yazdani J., ( 2015): Effect of acupressure with valerian oil $2.5 \%$ on the quality and quantity of sleep in patients with acute coronary syndrome in a cardiac intensive care unit, Journal of Traditional and Complementary Medicine;3:1-7

3. Bihari S., McEvoy D., Matheson E., Kims, Woodman R., \& Bersten A., (2012): Factors Affecting Sleep Quality of Patients in Intensive Care Unit. Journal of Clinical Sleep Medicine; 8(3): 301-307.

4. Carotenuto M., Gallai B., Parisi L., Roccella M., \& Esposito M., (2013): Acupressure therapy for insomnia in adolescents: a polysomnographic study. Neuropsychiatric Disease Treatment; 9 157:62.

5. Chen J., Chao Y., Lu S., Shiung T., \& Chao Y., (2012): The effectiveness of valerian acupressure on the sleep of ICU patients: a randomized clinical trial. International Journal of Nursing Studies; 49:913-920.

6. Daneshmandi M., Neiseh F., SadeghiShermeh M., \& Ebadi A., (2012): Effect of Eye Mask on Sleep Quality in Patients with Acute Coronary 
Syndrome. Journal of Caring Sciences; 1(3): 135143.

7. Delaney L., Van F., \& Lopez V., (2015): Sleeping on a problem: the impact of sleep disturbance on intensive care patients - a clinical review. Annals of Intensive Care; 5:3

8. Ellis B., Johns M., Lancaster R., Raptopoulos P., Angelopoulos N., \& Priest R., (1981): The St. Mary's Hospital Sleep Questionnaire: a study of reliability. Sleep;4:93-97

9. Jafarian A., Zabihi A., Babaie F., Sefidchian A., \& Bijanee A., (2011): Sleep quality and associated factors in hospitalized patients in Babol, Iran. Hormozgan University of Medical Sciences.;15(2):144-51.

10. Leigh T., Bird H., Hindmarch I., Constable P., \& Wright V., (1988): Factor analysis of the St. Mary s ${ }^{3}$ Hospital Sleep Questionnaire. Sleep; 11:448-453

11. Lewis S., Bucher L., Ruff S., Heitkemper M., \& Harding M., (2014): Medical -surgical nursing: assessment and management of clinical problems. $9^{\text {th }}$ ed. Mosby. An imprint of El Sevier Inc. printed in Canada; 730-750

12. Lytle J., Mwatha C., \& Davis K., (2016): effect of lavender aromatherapy on vital signs and perceived quality of sleep in the intermediate care unit: a pilot study. American journal of critical care; 23(1).

13. Mashayekhi F., Arab M., Pilevarzadeh M., Amiri M., \& Rafiei H., (2013): The effect of eye mask on sleep quality in patients of coronary care unit; Sleep Science;6(3)108-111

14. Moeini M., Khadibi M., Bekhradi R., Mahmoudian S., \& Nazari F., (2010): Effect of aromatherapy on the quality of sleep in ischemic heart disease patients hospitalized in intensive care units of heart hospitals of the Isfahan University of Medical Sciences. Iranian Journal of Nursing and Midwifery Research; 15(4): 234-239

15. Mullington J., Haack M., Toth M., Serrador J., \& Meier-Ewert H., (2012): Cardiovascular, Inflammatory and Metabolic Consequences of Sleep Deprivation, available in PubMed Central at http://www.ncbi.nlm.nih.gov/pmc/articles/PMC34 03737/\#R11

16. Neyse F., Daneshmandi M., Sadeghi M., \& Ebadi1 A., (2011): The effect of earplugs on sleep quality in patients with acute coronary syndrome. Iranian Journal of Critical Care Nursing; 4(3), 127 - 134

17. Oshvandi K., Abdi1 S., Karampourian A., Moghimbaghi A., \& Homayonfar S., (2014): The effect of foot massage on quality of sleep in ischemic heart disease patients hospitalized in
CCU, Iranian Journal of Critical Care Nursing 7(2):66-73

18. Polit D., \& Beck C., (2012): Nursing research: generating and assessing evidence for nursing practice. $9^{\text {th }}$ edition. Wolters Kluwer/Lippincott, Williams \& Wilkins. printed in china.

19. Reed M., (2014): acupressure Available at http://www.acupressure.com/

20. Sauvet F., Leftheriotis G., Gomez-Merino D., Langrume C., Drogou C., Van Beers P., Bourrilhon C., Florence G., \& Chennaoui M., (2010): Effect of acute sleep deprivation on vascular function in healthy subjects. Journal of Applied Physiology; 108(1):68-75.

21.Schiza S., Simantirakis E., \& Bouloukaki I., (2010): Sleep patterns in patients with acute coronary syndromes. Sleep Medicine;11:149153).

22. Shahid A., Wilkinson K., Marcu S., \& Shapiro C. (2012): STOP, THAT and One Hundred Other Sleep Scales, springer science + business media, chapter 89, P363

23. Shariati A., Jahani S., Hooshmand M., \& Khalili N., (2012): The effect of acupressure on sleep quality in hemodialysis patients. Complementary Therapies in Medicine; 20:417423.

24. Viana S., \& Filomena M., (2014): Factors that affect inpatients' quality of sleep, SciELO Analytics available at: http://www.scielo.br/scielo.php?pid=S008062342 013000100006\&script=sci_arttext\&tlng=en

25. Waits A., Tang Y., Cheng H., Tai C., \& Chien L., (2016): Acupressure effect on sleep quality: A systematic review and meta-analysis. Sleep Medicine Reviews

26. Wang L., Cheng W., Sun Z., Xu Y., Cheng G., Gaischek I., Kuang H., \& Litscher G., (2013): Ear acupressure, heart rate, and heart rate variability in patients with insomnia. EvidenceBased Complementary and Alternative Medicine

27. Waterhouse J., Fukuda Y., \& Morita T., (2012): Daily rhythms of the sleep-wake cycle. Journal of Physiological Anthropology;31:5

28. Yeung W., Chung K., Poon M., Ho F., Zhang S., Zhang Z., Ziea E., \& Wong V., (2012): Acupressure, reflexology and auricular acupressure for insomnia: a systematic review of randomized controlled trials. Sleep Medicine; 13(8):971-984.

29.Zolfaghari M., Afshar P., Noghabi A., \& Khameslou A., (2013): Modification of environmental factors on quality of sleep among patients admitted to CCU. Hayat Journal; 18(4):61-68 